is a carrier there can be no stigma. Most couples would prefer to know before conception if both partners carry the same gene defect. Few have difficulty accommodating the need to care for the sick who exist while taking steps to avoid recurrence. The minority who chose to continue to term would need support. Nevertheless, experience shows that, in Britain at least, most couples would opt for a healthy child.

In short, the capacity to screen for carriers of cystic fibrosis is set eventually to carry genetics if not into every living room, at least into every health centre. For it is there that most people would prefer to have such investigations. ${ }^{4}$ Is it now time to start the general introduction of genetic screening? The two studies reported in this issue explore the options and illustrate many of the problems.

The paper by Bekker and colleagues introduced a member of the research team to a London practice ( $p$ 1584). ${ }^{5}$ A lack of interest in carrier testing emerges, which is perhaps unsurprising: an inner city practice will always be a tough test of any preventive programme. The authors found that the only effective screening option in terms of uptake was to collect samples opportunistically, a similar finding to that reported by Watson et al. ${ }^{6}$ Although the authors feared that this might reflect inappropriate "selling" of the test, it seems at least as likely that people will not inconvenience themselves for a test that they do not think they need. People without a family history "feel lucky."

Harris and colleagues got general practitioners in several practices to target the first antenatal visit (p 1580). ${ }^{7}$ Enthusiasm among general practitioners in Manchester may have reflected the persuasive powers of the study group, but a more likely explanation is that, given adequate support, general practitioners have a natural affinity for the study of genetic disorders in families and adapt readily, using the cystic fibrosis carrier test as a means of introduction.

Different approaches to carrier testing are likely to be complementary; our own pilot study is looking at using a preconception clinic, a "well couple" clinic. Most regional genetic centres now offer cascade carrier detection ${ }^{8}$ by approaching the relatives of known carriers. This has the advantage of precision and limited cost but depends on the birth of an affected child. Testing in antenatal clinics is feasible ${ }^{9}$ but introduces additional stress on the family and the system. Telling couples only if both carry the gene ${ }^{10}$ reduces the need for counselling but is counter to the longer term need for the population to recognise that recessive carrier status is a normal fact of life. This could be merged with the health centre's antenatal booking clinic to make genetic advice available to couples planning, or about to have, a baby.

Introducing carrier screening to senior school students and linking it to a health education programme ${ }^{11}$ is a possible "turnstile" for the future. Our first need is to educate the health care professionals. At the end of this decade couples will want to know which recessive genes they carry. If they don't get the answer they will at least expect their doctor to understand the question.

Carrier testing cannot easily be blocked by purely economic arguments as the fall in health costs from fewer children born with cystic fibrosis would more than offset the cost of screening.' It seems set to come into wider use with the usual debate over resources, cost-benefit analysis, public understanding, the changing clinical burden, and the ethics of termination. It heralds the beginning of true primary care genetics. Should it perhaps be called family practice?

JOHN BURN

Northern Region Genetics Service and Professor of clinical genetics

Division of Human Genetics,

University of Newcastle upon Tyne,

Newcastle upon Tyne NE2 4AA

1 Burn J, Magnay D, Claber O, Curtis A. Population screening in cystic fibrosis. $\mathcal{F} R$ Soc Med 1993;86(suppl 20):2-6.

Clarke A. Genetics, ethics and audit. Lancet 1990;335:1145-7.

3 Modell B. Prenatal diagnosis and genetic screening: community service implications. London: Royal College of Physicians, 1989.

Magnay D, Wilson O, El Hait S, Balhamar M, Burn J. Carrier testing for cystic fibrosis: knowledge and attitudes within a local community. I R Coll Physicians Lond 1992;26:69-70.

5 Bekker H, Modell M, Denniss G, Silver A, Mathew C, Bobrow M, et al. Uptake of cystic fibrosis testing in primary care: supply push or demand pull? $B M \mathcal{F}^{1993 ; 306: 1584-6 .}$

6 Watson EK, Mayall E, Chapple J, Dalziel M, Harrington K, Williams C, et al. Screening for carriers of cystic fibrosis through the primary care services. BMf 1991;303:504-7.

7 Harris H, Scotcher D, Hartley N, Wallace A, Craufurd D, Harris R. Cystic fibrosis carrier testing in early pregnancy by general practitioners. $B M F$ 1993;306:1580-3.

8 Super M, Schwarz MJ, Malone G. Screening for cystic fibrosis carriers. Lancet 1992;340:490-1.

9 Mennie ME, Gilfillan A, Compton M, Curtis L, Liston WA, Pullen I, et al. Prenatal screening for cystic fibrosis. Lancet 1992;340:214-6.

10 Wald NJ. Couple screening for cystic fibrosis. Lancet 1991;338:1318-9.

11 Turner G. Viewpoint: carrier screening. Bulletin of the Human Genetics Society of Australasia 1990;3(3):8.

\title{
Who's for continuous ambulatory peritoneal dialysis?
}

\section{Most patients with end stage renal failure, especially those with a chance of receiving a transplant}

Continuous ambulatory peritoneal dialysis is now an established treatment for patients with end stage renal failure and accounts for over half the patients managed with dialysis in Britain. ${ }^{\prime}$ Despite teething troubles in the early $1980 \mathrm{~s}^{2}$ patient survival is currently the same with both continuous ambulatory peritoneal dialysis and haemodialysis, and the survival of the technique of continuous ambulatory peritoneal dialysis is approaching that of haemodialysis. ${ }^{13}$ Morbidity is similar, ${ }^{34}$ but the rate of admission to hospital is lower with haemodialysis. ${ }^{35}$

Yet the proportion of patients treated with continuous ambulatory peritoneal dialysis varies considerably from country to country: whereas in Britain it is $52 \%$, in Sweden it is $33 \%$, in the United States $17 \%$, in Germany $9 \%$, and in Japan $6 \%$. Why are patients preferentially given haemodialysis in most parts of the developed world?

Non-medical considerations seemingly have a substantial impact on the choice of treatment, with financial factors predominating. ${ }^{6}$ The rates of use vary according to how much doctors and renal units are reimbursed for treatment. Countries with fixed annual allocations for health care favour continuous ambulatory peritoneal dialysis, presumably because it is cheaper.

This most obviously occurs where facilities for maintenance haemodialysis are limited, as in Britain. In countries where reimbursement differs less between continuous ambulatory peritoneal dialysis and haemodialysis, the lack of adequate training of nephrologists and nurses, bias among doctors, the availability of resources, and social mores are more important.

The only genuine medical contraindications to continuous ambulatory peritoneal dialysis are active bowel disease, abnormalities of the abdominal wall, and the inability to learn or perform the technique. Although more high risk patients 
(those with diabetes or cardiovascular or psychosocial problems and elderly patients) are being accepted for dialysis, most of them are suitable for peritoneal dialysis. How then is the best treatment chosen for a particular patient? Ideally patients should decide unless strong medical reasons exist for one particular treatment. Doctors and nurses may not always appreciate what patients consider important or what would suit them best. ${ }^{?}$

\section{Money talks}

Moreover, once patients abrogate the decision over choice of treatment they become subject to the choice of their doctors, who may be biased by financial considerations. ${ }^{6}$ In Britain the lack of facilities for the more expensive maintenance haemodialysis limits free choice; two thirds of new patients receive continuous ambulatory peritoneal dialysis as their initial treatment. ${ }^{5}$

Who then is currently for continuous ambulatory peritoneal dialysis in Britain? "Young patients" (those under 60) with a reasonable opportunity of transplantation are candidates for home peritoneal dialysis. Patients suitable for either modality and preferring continuous ambulatory peritoneal dialysis are another obvious group.

Patients with other conditions like diabetes and severe cardiovascular disease may be better treated with peritoneal dialysis. Undoubtedly, however, a core of patients exists who have to undergo continuous ambulatory peritoneal dialysis even though maintenance haemodialysis would suit them better. Their number is unknown, but the proportion of patients receiving continuous ambulatory peritoneal dialysis would fall if suitable haemodialysis facilities were available.

Several factors prevail in Britain that will preserve the status quo. Firstly, the rate at which new patients with end stage renal failure are accepted for dialysis has increased to an average of 60 per million each year, ${ }^{1}$ with some regions exceeding 80 patients per million-the current target based on studies of incidence. ${ }^{8}$ Any increase in the rate of acceptance for dialysis (which is both justifiable and desirable) would therefore have considerable resource implications with increasing need for maintenance haemodialysis - a commodity likely to remain in short supply. Secondly, with the internal market, price will emerge as the main factor in deciding between similar treatments.

Contracts for continuous ambulatory peritoneal dialysis should specify standards of care and staffing requirements. ${ }^{9}$ They should include technological advances that are expensive but of proved value (such as disconnect systems that reduce peritonitis, ${ }^{10}$ physiological dialysis fluids, ${ }^{11}$ and automated dialysis techniques); the care of high risk patients; and the need to provide increased haemodialysis and ward back up. ${ }^{5}$ All these factors reduce the difference in cost between $\equiv$ continuous ambulatory peritoneal dialysis and haemodialysis.

Currently evolving practice, though still in its infancy, suggests that purchasers may be attracted to the cheaper peritoneal dialysis even when adequately informed of the choices. One way to tackle the increasing financial burden of renal dialysis (and the limited budgets of renal units) is for units to share costs with general practitioners (through their prescribing budgets). About half of current patients' costs are met this way, although this practice is much more expensive (because of the need for dispensing fees and the absence of discounts for bulk purchases).

The future of the renal services ultimately rests with the purchasers; herein lies the chance to reform the service to the overall advantage of patients. This will only happen if money follows the patients, whose referrals continue.

R GOKAL

Manchester Royal Infirmary, Consultant nephrologist $\mathrm{O}$

Manchester M13 9WL

1 Raine AEG, Margreiter R, Brunner FP, Ehrich J, Geerlings W, Landais P, et al. Report on management of renal failure in Europe, XXII, 191. Nephrol Dial Transpl 1992;7(suppl 2):7-35.

2 CAPD for chronic renal failure [editorial]. Lancet 1980;ii:1172-3.

3 Maiorca R, Cancarini C, Brunore G, Camerini C, Manili L. Morbidity and mortality of CAPD and haemodialysis. Kidney Int 1993;43(suppl 40):S4-15.

4 Churchill DM. Comparative morbidity among haemodialysis and continuous ambulatory peritoneal dialysis patients. Kidney Int 1992;43(suppl 40):S16-22.

5 Gokal R, Jakubowksi C, King J, Hunt L, Bogle S, Baillod R, et al. Outcome in patients on CAPD and haemodialysis: 4 year analysis of a prospective multicentre study. Lancet 1987;ii:1105-9.

6 Nissenson AR, Prichard SS, Cheng I, Gokal R, Kuboto M, Maiorca R, et al. Non medical factors that impact on ESRD modality selection. Kidney Int 1993;43(suppl 40):S1 20-7.

7 Groome PA, Hutchinson TA, Prichard SS. ESRD treatment modality selection; which factors are important in the decision? Advances in Peritoneal Dialysis 1991;7:54-7.

8 Feest TG, Mistry CS, Grimes D, Mallick NP. Incidence of advanced chronic renal failure and the need for end stage renal replacement treatment. $B M Y$ 1990;301:897-900.

9 Renal Association. Provision of services for adult patients with renal disease in the United Kingdom London: Renal Association, 1991.

10 Maiorca R, Cantaluppi A, Cancarini GC, Scalamogna A, Broccoli R, Graziani G, et al. Prospective controlled trial of a Y connector and disinfectant to prevent peritonitis in CAPD. Lancet 1983;ii:642-4.

11 Hutchison A, Gokal R. Improved solutions for peritoneal dialysis; physiological calcium solutions, osmotic agents and buffers. Kidney Int 1992;42(suppl 38):S153-9. 